\title{
Overweight and Obesity in High Stress Workplaces
}

\section{${\text { Pouran Faghri* }{ }^{1 *} \text { and Christina Mignano }}^{2}$}

${ }^{1} M D, M S, F A C S M$, Professor of Health Promotion Sciences, University of Connecticut, USA

${ }^{2} B S, R D$, University of Connecticut, USA

High stress workplaces, characterized by high job demands and low job control, have been associated with increased risk for cardiovascular disease, high blood pressure, high blood sugar, and high cortisol levels [1]. Increasingly, evidence suggests overweight and obesity risk may be related to high demand, low-control work environments and extended work hours. High-stress employees often report poor eating habits, low level of physical activity, smoking/alcohol use, and weight gain [2-4]. High stress work can also lead to psychological issues including anxiety and depression [5].

According to the U.S. National Institute for Occupational Safety and Health, job stress is defined as "the harmful physical and emotional responses that occur when the requirements of a job do not match the capabilities, resources, or needs of the worker." Such stressors can affect both physical and mental health through the acceptance and practice of unfavorable lifestyle behaviors [6,7] consequently increasing the risk for weight gain and obesity. Much research has shown that stress can affect lifestyle choices and health behaviors such as food consumption and physical activity $[8,9]$, leading to overweight and obesity. Although the relationship between work stress and weight gain is not fully understood [10], it is important to clarify the sources of stress that may affect weight gain and the overall well-being of employees in stressful workplaces [7].

Correctional employees are an example of a high stress work group. The unique occupational environment of corrections exposes officers to daily stress related to personal safety and the organizational hierarchy system. Nearly half of correctional officers report that their job is "emotionally tough" [11]. Common stressors among officers include shift work, overtime, low social support, a negative public image, hierarchal management, work overload, role ambiguity, lack of recognition, as well as job-demands-control imbalance and effort-toreward-imbalance [12-17]. "Moreover", unhealthy lifestyle, including lack of physical activity and unhealthy diet, further put correctional staff at risk for other chronic conditions. Compared to the general U.S. population, correctional staff have higher overweight rates $(86.6 \%$ vs. $66 \%)$ and obesity rates (55.8\% vs. $32 \%)$ [18]. Furthermore, the rate of chronic diseases such as myocardial infarction, high blood pressure, diabetes, asthma, and ulcers are significantly higher compared to employees in other occupations. Alarmingly the reported average lifespan of a correctional officer is 59 years of age, which is 16 years shorter than the national average [19].

In a structured interview by Morse et al. [5] corrections officers reported that they are under constant stress as they must be prepared to respond to emergency situations such as inmate fights, noxious inmates, attacks on officers, hyper-vigilance, inmate related injuries, and disease exposure. In addition, the organizational structure, ambiguous rules, and hierarchical relationship between management and staff cause further stress and job dissatisfaction. There are reports of high prevalence of mental health issue amongst correctional staff including perception of a short life expectancy, poor work-family balance, and high rates of suicide and depression [20,21].

In addition to stress increasing risk of obesity, the interplay between environmental factors such as access, availability, and affordability of high-energy dense foods and sedentary behaviors promotes a positive energy balance (increased energy consumption; decreased energy expenditure) and an increased risk of obesity. Employees who are working long hours, overtime, or shift work experience higher levels of fatigue and tend to be more sedentary and engage in few leisure activities, leading to obesity [22]. Due to rigid security protocols at the correctional institution, correctional officers are often required to remain sedentary for long periods of time, with no opportunity to leave the facility to participate in structured physical activity [23]. Moreover, a sedentary lifestyle and working odd shifts (shift work, extended shifts and rotating shifts) leads to increased sleepiness [24], decreased alertness and a higher probability of snacking on high-calorie, lownutrient foods for energy [14].

Workplace health promotion and wellness programming has been gaining attention in recent years for improving employees' health, reducing absenteeism, increasing productivity, and eventually reducing heath care cost. However, implementing these programs requires special attention to work organization, job characteristics, and management supports. Consequently, effective worksite health promotion planning is not a "one size fits all" approach.

With the high rates of poor mental and physical health amongst high-stress occupations such as corrections, effective health promotion programs are imperative. This need is further evidenced by governmental agencies recognizing the need to improve the health of public safety workers, including reducing occupational stressors in correctional personnel [25]. To provide maximally effective wellness programs, program planners must consider all factors affecting employee health, both organizational and environmental. Commonly reported barriers to the success of traditional health promotion programs (2004 National Worksite Health Promotion Survey) are lack of employee interest, staff resources, funding, participation of high-risk employees, and management support. Furthermore, unique workplace barriers such as rotating shifts, inflexible schedules, and lack of job control have been reported and must be addressed to ensureprogram success and longevity. To overcome such barriers, evidence- based health promotion programming is recommended. Such programs should include employees participation and input into the program so unique work and organizational characteristics are incorporated into program planning and implementation. More specifically the workplace structure, cultural norms, decision-making and problem solving processes should be integrated. Participation by the employees may empower them to make changes to their workplace that are meaningful to the employees and positively received by the workforce.

Finally, employers should work with health care professionals, supervisors should promote a culture of wellness, and individuals need

*Corresponding author: Pouran Faghri, Professor of Health Promotion Sciences University of Connecticut, USA, E-mail: pouran.faghri@uconn.edu

Received August 29, 2013; Accepted August 30, 2013; Published September 02, 2013

Citation: Faghri P, Mignano C (2013) Overweight and Obesity in High Stress Workplaces. J Nutr Disorders Ther 3: e110. doi:10.4172/2161-0509.1000e110

Copyright: $\odot 2013$ Faghri P, et al. This is an open-access article distributed under the terms of the Creative Commons Attribution License, which permits unrestricted use, distribution, and reproduction in any medium, provided the original author and source are credited. 
Citation: Faghri P, Mignano C (2013) Overweight and Obesity in High Stress Workplaces. J Nutr Disorders Ther 3: e110. doi:10.4172/21610509.1000e110

to perceive their health as a priority in order to make healthy behavior change.

\section{References}

1. Karasek RA, Theorell T (1990) Healthy work: Stress, productivity and the reconstruction of working life. Basic Books, New York, NY.

2. Winick C, Rothacker DQ, Norman RL (2002) Four worksite weight loss programs with high-stress occupations using a meal replacement product. Occup Med 52: 25-30.

3. Karasek R, Baker D, Marxer F, Ahlbom A, Theorell T (1981) Job decision latitude, job demands, and cardiovascular disease: a prospective study of Swedish men. Am J Public Health 71: 694-705.

4. Kouvonen A, Kivimaki M, Cox SJ, Cox T, Vahtera J (2005) Relationship between work stress and body mass index among 45, 810 female and male employees. Psychosom Med 4: 577-583.

5. Morse T, Dussetschleger J, Warren N, Cherniack M (2011) Talking about health: correction employees' assessments of obstacles to healthy living. J Occup Environ Med 53: 1037-1045.

6. Fernandez ID, Su H, Winters PC, Liang H (2010) Association of workplace chronic and acute stressors with employee weight status: data from worksites in turmoil. J Occup Environ Med 1: S34-S41.

7. Senol-Durak E, Durak M, Gencoz T (2006) Development of work stress scale for correctional officers. J Occup Rehabil 16: 157-168.

8. McCraty R, Atkinson M, Lipsenthal L, Arguelles L (2009) New hope for correctional officers: an innovative program for reducing stress and health risks. Appl Psychophysiol Biofeedback 34: 251-272.

9. Wardle J, Chida Y, Gibson EL, Whitaker KL, Steptoe A (2011) Stress and adiposity: a meta-analysis of longitudinal studies. Obesity (Silver Spring) 19: 771-778.

10. Caban AJ, Lee DJ, Fleming LE, Gomez-Marin O, LeBlanc W, Pitman T (2005) Obesity in US workers: The National Health Interview Survey, 1986 to 2002. Am J Public Health 94: 1614-1622.

11. Ghaddar A, Mateo I, Sanchez P (2008) Occupational stress and mental health among correctional officers: a cross-sectional study. J Occup Environ Med 50: 92-98.

12. Dignam JT, Barrera M, Jr, West SG (1986) Occupational stress, social support, and burnout among correctional officers. Am J Community Psychol 14: 177193.
13. Hannerz H, Albertsen K, Nielsen ML, Tuchsen F, Burr H (2004) Occupational factors and 5-year weight change among men in a danish national cohort. Health Psychol 23: 283-288.

14. Kivimaki M, Head J, Ferrie JE, Shipley MJ, Brunner E, et al. (2006) Work stress, weight gain and weight loss: evidence for bidirectional effects of job strain on body mass index in the Whitehall II study. Int J Obes 30: 982-987.

15. Oginska-Bulik N (2005) Emotional intelligence in the workplace: exploring its effects on occupational stress and health outcomes in human service workers. Int J Occup Med Environ Health 18:167-175.

16. Ramey SL, Downing NR, Franke WD (2009) Milwaukee police department retirees: cardiovascular disease risk and morbidity among aging law enforcement officers. AAOHN J 57: 448-453.

17. Schaufeli WB, Peeters MCW (2000) Job Stress and Burnout among Correctional Officers: A Literature Review. International Journal of Stress Management 7: 19-48.

18. Ferraro L, Faghri PD, Henning R, Cherniack M (2013) Center for the Promotion of Health in the New England Workplace Team Workplace-based participatory approach to weight loss for correctional employees. J Occup Environ Med 55 147-155.

19. Cheek FE (1984) Stress Management for Correctional Officers and Their Families. American Correctional Association, Alexandria, VA.

20. Stack S, Tsoudisa O (1997) Suicide risk among correctional officers: a logistic regression analysis. Archives of Suicide Research 3:183-186.

21. Agid O, Kohn Y, Lerer B (2000) Environmental stress and psychiatric illness Biomed Pharmacother 54: 135-141.

22. Yamada Y, Ishizaki M, Truritani I (2002) Prevention of Weight Gain and Obesity in Occupational Populations: A New Target of Health Promotion Servicers at Worksites. Journal of Occupational Health 44: 373-384.

23. Leino TM, Selin R, Summala H, Virtanen M (2011) Violence and psychologica distress among police officers and security guards. Occup Med 61: 400-406.

24. Charles LE, Gu JK, Andrew ME, Violanti JM, Fekedulegn D, et al. (2011) Sleep duration and biomarkers of metabolic function among police officers. J Occup Environ Med 53: 831-837.

25. (2013) NORA Public Safety Council. National Occupational Research Agenda (NORA) National Public Safety Agenda. 